Produto \& Produção, vol. 12, n. 1, p. 60 - 90, fev. 2011

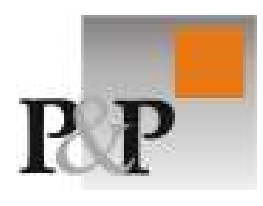

\title{
Uma Investigação sobre os Benefícios e Dificuldades na Adoção da Modularidade em uma Montadora de Automóveis
}

\author{
José Antonio Carnevalli \\ Departamento de Engenharia de Produção, Escola Politécnica, USP
}

Angelo Varandas Júnior

Departamento de Engenharia de Produção, Escola Politécnica, USP

Paulo Augusto Cauchick Miguel

Departamento de Engenharia de Produção, Escola Politécnica, USP

As mudanças no cenário competitivo internacional vêm impulsionando transformações na indústria automotiva, com destaque para o desenvolvimento de novos produtos, processos produtivos e as configurações da cadeia de suprimentos. Uma aplicação crescente no desenvolvimento de novos produtos é a adoção da modularidade. Baseada na divisão de um produto complexo em subsistemas independentes, a modularidade possibilita o projeto de produtos e de processos de produção a partir de subsistemas, que são desenvolvidos individualmente, porém funcionam de forma integrada. Nesse contexto, o objetivo geral desse trabalho é investigar a adoção dos princípios da modularidade em uma montadora de automóveis, analisando variáveis relacionadas ao projeto modular e de cooperação com os fornecedores na cadeia de suprimentos automotiva. Estas variáveis são investigadas por meio da abordagem de estudo de caso, com a coleta de dados realizada por entrevista semi-estruturada, posterior transcrição e análise de conteúdo, resultando então na descrição e análise do caso no contexto da investigação. Os resultados identificaram convergência dos resultados da empresa estudada com a literatura, destacando-se benefícios e dificuldades na adoção da modularidade, bem como aspectos relevantes associados aos fornecedores. Como perspectivas futuras, é importante investigar o desenvolvimento de um novo produto com arquitetura modular e suas conseqüências para os processos organizacionais relacionados à produção, qualidade e outros.

The changes in the competitive international scenario have imposed transformations in the automotive industry with regard to new product development (NPD), production and supply chain. An growing application in NPD is the adoption of modularity. It is based on the division of a complex product in independent subsystems enabling product and process design from subsystem individually developed but integrated functioning. In this context, the general objective is to investigate the adoption of modularity in a car assembler. It analyses variables related to modular design and cooperation with suppliers within the automotive supply chain. These variables are investigated through case-based research, with data collected by a semi-structured interview with content analysis done a posteriori. The results indicated a convergence of results to the literature. Benefits and difficulties associated with 
modularity are emphasised as well as relevant aspects concerning suppliers. As future work, it is important to further investigate the development of a modular product and its consequences to other organizational processes related to production, quality, and so on.

\section{1. . INTRODUÇÃO}

Atualmente, as empresas são impulsionadas a otimizar seus recursos, adaptar-se à dinâmica global e satisfazer às necessidades de consumidores cada vez mais exigentes. Uma das alternativas estratégicas adotadas para melhorias nesse processo é a implantação da modularidade, que tem como principais objetivos (BALDWIN e CLARK, 2004): (i) facilitar o gerenciamento de produtos e processos complexos, por meio da divisão em módulos mais simples; (ii) possibilitar atividades de produção em paralelo, já que os módulos podem ser manufaturados simultaneamente; e (iii) adaptar a produção às incertezas futuras, pois o produto final pode ser modificado pela adaptação de um único módulo, que exige um custo mais baixo do que refazer o produto por completo.

Nesse contexto, o escopo deste trabalho considera uma busca na literatura sobre o tema, abordando os seus diferentes tipos, bem como sua aplicação, benefícios e dificuldades na sua adoção. Além disso, faz uma análise da distribuição e classificação dos principais trabalhos desenvolvidos sobre este tema no setor industrial automobilístico. O foco nesse setor industrial é justificado pela sua intensa e constante concorrência, que impulsiona as montadoras automotivas a estarem em constante evolução e, ainda, por aplicar há algum tempo o conceito de modularidade. As mudanças no cenário competitivo internacional, a fragmentação de mercados e a dinâmica da evolução tecnológica vêm impulsionando profundas transformações na indústria automotiva, com destaque aos processos produtivos e à configuração da cadeia de suprimentos. Assim sendo, as atividades de projeto, manufatura, vendas e relações com o mercado, envolvem uma definição eficaz da arquitetura organizacional e de produção (STURGEON, 2002). Esta concentração de valor nas estruturas organizacionais dos fabricantes de veículos (OEM - Original Equipment Manufacturer - Fabricantes de Equipamento Original, como as montadoras de veículos), ao longo do tempo, estabelece limitações nas operações de seus fornecedores. Diante disso, algumas montadoras e seus fornecedores têm adotado as práticas de modularidade como estratégia para a maximização dos lucros, por meio da padronização de componentes, flexibilidade na linha de produção, e emprego de plataformas globais (PINE, 1992; SANCHEZ e MAHONEY, 1996). Baldwin e Clark (1997) acrescentam que a modularidade é igualmente utilizada no projeto de produtos e processos complexos a partir de subsistemas, que são desenvolvidos individualmente, porém funcionam de forma integrada. Desta maneira, permite-se a produção de produtos diversificados por meio da combinação destes subsistemas (YIGIT et al., 2002; LEE et al., 2001), além de possibilitar ganhos com a alteração da configuração dos processos produtivos, como no caso da planta da VW de Resende (COLLINS et al., 1997).

Entretanto, a decisão de se adotar um projeto modular encontra-se ainda em início de desenvolvimento na literatura e, comparado a modularidade na produção, existem poucas evidências empíricas de suas vantagens e dificuldades, como por exemplo, quanto ao processo de transferência das atividades de projeto no 
desenvolvimento de novos produtos aos fornecedores de módulos. Esta prática envolve muitas responsabilidades, interfaces e transferência de competências entre montadoras e fornecedores, que se não realizadas adequadamente podem gerar riscos aos envolvidos e perda de conhecimento (know-how).

Nesse contexto, o presente trabalho busca avaliar a adoção da modularidade na organização e o meio no qual ela está inserida. $O$ objetivo principal é investigar a adoção dos princípios da modularidade em uma montadora automotiva e, também, de analisar algumas variáveis relacionadas ao tema, tais como: a adoção do projeto modular, a cooperação com os fornecedores no desenvolvimento de um novo produto, a transferência de atividades para os fornecedores, os benefícios e dificuldades associadas à adoção da modularidade, e a organização dos fornecedores em um condomínio modular. Estas variáveis são verificadas por meio da abordagem de estudo de caso, com a coleta de dados realizada por meio de entrevista semi-estruturada, com posterior transcrição e análise de seu conteúdo, resultando então no caso e seu contexto de investigação.

\section{REFERENCIAL TEÓRICO SOBRE A MODULARIDADE}

As empresas do setor automotivo têm buscado como estratégia para reduzir os custos de produção, a padronização de componentes e o compartilhamento de módulos na busca da diversificação de produtos. Desta forma, vem sendo desenvolvidas famílias de produtos para customização em massa e compartilhamento dos riscos de projeto com os fornecedores (CAMUFFO, 2000; DORAN, 2003). Assim sendo, a abordagem de arquitetura de produto considera uma estrutura para definir os sub-sistemas e componentes de cada novo produto, uma vez que um produto é constituído por diversos componentes físicos que atuam com recursos específicos para realizar determinadas funções. A arquitetura do produto descreve como estes componentes são organizados e como eles se interagem funcionalmente; deve compreender os seguintes tópicos (MIKKOLA e GASSMANN, 2003): o arranjo entre os elementos funcionais, um mapeamento dos elementos funcionais para os componentes físicos e a especificação das interfaces entre os componentes físicos que interagem entre si.

$\mathrm{Na}$ realidade, uma arquitetura do produto pode ser classificada em integrada ou modular (HUANG, 2000). A arquitetura integrada é concebida a partir de subsistemas que são projetados de forma dependente cujas funções são compartilhadas por um ou mais desses módulos. No projeto modular, a arquitetura é concebida a partir de subsistemas que são projetados independentemente (interfaces desacopladas), mas que funcionam integralmente juntos, onde cada módulo pode exercer uma ou mais funções, como no caso de computadores pessoais, automóveis, aviões, dentre outros.

Segundo Fixson (2003), os módulos têm como função principal atender a determinadas características, tais como: capacidade de submeter-se a testes funcionais, ajustabilidade, padronização das interfaces, intercambiabilidade, transportabilidade, fraca interdependência entre eles e alta interdependência dentro deles. Para Langlois (2002), a modularidade também é um importante grupo de princípios para administrar a complexidade, pois os sistemas complexos são separados em partes que se comunicam umas com as outras por meio de interfaces padronizadas dentro de uma estrutura também padronizada. 
Esta definição dos tipos de arquitetura propicia efeitos positivos na variabilidade dos produtos, sugerindo que a arquitetura modular permite maior flexibilidade de projeto e manufatura pela utilização de subsistemas que são relativamente independentes, conectados por interfaces padronizadas (ARNHEITER e HARREN, 2006; CAUCHICK MIGUEL, 2005). A interface é a conexão entre os módulos e permite a montagem de diferentes variantes. A especificação dessas interfaces é vista como o principal item na modularização e facilita o sucesso na diversificação do produto. Nesse sentido, alguns benefícios são apontados com a aplicação da modularidade (ISHII e YANG, 2003): atualizações eficientes, complexidade reduzida, menores custos, maior facilidade de teste, diagnóstico de falhas e manutenção nos produtos, desenvolvimento rápido de produtos e melhor estruturação de conhecimento do projeto.

A modularidade também pode ser definida como o processo de conceber um produto complexo a partir de subsistemas de menor escala, que podem ser projetados independentemente, mas que funcionam operam juntos como um todo (BALDWIN E CLARK, 1997). Existe então uma interdependência entre os subsistemas e componentes do próprio módulo e a independência entre os módulos. No entanto, é importante destacar que a modularidade não é limitada ao projeto de produto podendo envolver também os processos de produção. Neste sentido, estes demais tipos de modularidade são descritos na seqüência.

\subsection{Tipos de Modularidade e sua Aplicação no Setor Automotivo}

A modularidade pode ser classificada em três categorias (BALDWIN e CLARK, 2000): de projeto (ou de desenvolvimento de produto), de processo (ou de produção) ou de uso. A modularidade de projeto define o produto, cada um de seus módulos e respectivos componentes e a relação funcional entre eles, como destacado anteriormente. É nesta etapa que a função de cada subsistema é especificada, bem como suas interfaces. Já a modularidade de processo busca simplificar os processos de produção (manufatura e montagem), que podem ser divididos em etapas melhor definidas. Além disso, pode reduzir o tamanho da linha de montagem da fábrica, pois a submontagem dos módulos podem ser transferidas para os fornecedores (CONNOLLY, 2007; HOLMES, 2004), o que também reduz o tempo de montagem na empresa (DORAN, 2002). Deste modo, os fornecedores podem ser responsabilizados por alguns processos de submontagens e testes de pré-acoplamento (CAMUFFO, 2000). Por fim, tem-se o conceito da modularidade de uso, que tem como objetivo satisfazer as necessidades de diferentes clientes e realização de customização em massa (PANDREMENOS et al., 2009), por meio da personalização do produto (GU e SOSALE, 1999) ou mudanças de suas funções pela alteração de alguns módulos (CEPOLINA e MICHELINI, 2003). Cada uma dessas categorias é mais detalhada a seguir.

A modularidade no desenvolvimento de produto pode ser aplicada em diversos setores industriais, tais como: eletrônico, telecomunicações, aeronáutica, naval, serviços bancários, seguros e outros (ANDO, 2004). No setor de informática, por exemplo, a modularidade teve um papel fundamental no desenvolvimento dos computadores mainframe (System 360) da IBM, permitindo que cada consumidor pudesse agregar diferentes módulos $e$, assim, adaptar 0 produto às suas necessidades (BALDWIN e CLARK, 2000). Na indústria automobilística brasileira e 
mundial, pode ser verificada uma tendência crescente de implementação da arquitetura modular, sendo que no Brasil a modularidade é aplicada na indústria automotiva desde a segunda metade da década de 90 (SALERNO et al., 2009). Esse fato leva a crer que é importante e necessária uma investigação mais aprofundada de suas principais características e conseqüências, principalmente, em relação ao desenvolvimento de novos produtos.

\subsubsection{Modularidade no Projeto do Produto}

A modularidade aplicada ao projeto de produto possibilita o aumento da parceria entre a empresa com seus fornecedores dos módulos (De MELLO e MARX, 2007), que podem passar a ser responsáveis por parte do projeto destes, o que é indicado nos resultados de uma survey realizada no início da década no Brasil, com 224 fornecedores do setor automotivo (ZILBOVICIUS et al., 2002). Segundo os autores supra-citados, verificou-se neste estudo que dos fornecedores de módulos, $76 \%$ tem atividades de projeto (atividades de co-design). Assim, esses fornecedores podem se tornar especialistas de um determinado módulo, o que impulsionaria o avanço tecnológico nessa área específica. Porém, na indústria automotiva, a modularidade no projeto de produto é a menos explorada (BALDWIN e CLARK, 1997), apesar de apresentar uma tendência de crescimento (PANDREMENOS et al., 2009), como no caso da VW do Brasil que transfere parte dos projetos para fornecedores, sempre mantendo o controle de parte do projeto de cada módulo (De MELLO e MARX, 2007). Em geral, no ocidente a tendência das montadoras é centrar esforços na modularidade de produção enquanto que a indústria automotiva japonesa é mais atuante na adoção da modularidade no projeto de produto (PANDREMENOS et al., 2009).

Existem dois tipos de informações que guiam um projeto: as visíveis (ou normas) e as invisíveis. As informações normativas são praticamente imutáveis e estabelecidas na fase inicial do projeto pelas montadoras, responsáveis pela integração do produto final. Esses tipos de informações determinam não somente cada módulo, suas interações, suas funções (como unidade e como sistema) e os seus elementos físicos, como também seus ajustes, conexões e comunicações. Além disso, as normas visam garantir que cada módulo esteja em funcionamento adequado individualmente e um em relação ao outro (GRAZIADIO, 2004). Ainda segundo a autora, em contrapartida, as informações invisíveis são aquelas determinadas pelo projetista do módulo e suas eventuais modificações dispensam notificações aos arquitetos do sistema devido à independência entre os módulos.

As inovações tecnológicas dos módulos e sistemas têm grande potencial de ocorrer, já que está crescendo a concorrência entre poucas empresas fornecedoras, que estão cada vez mais assumindo o projeto de produto (BALDWIN e CLARK, 1997). Porém, isso não acontece de forma acelerada, pois as montadoras preferem estabelecer a maior parte das informações como sendo normativas. Assim, elas mantêm o conhecimento estratégico do mecanismo de funcionamento das interfaces entre os módulos. Como desvantagem, as novas idéias e inovações por parte dos fornecedores são prejudicadas. 


\subsubsection{Modularidade de processo (ou de produção)}

A modularidade de produção é a mais aplicada na indústria automotiva, pois é nessa etapa que as montadoras objetivam aumentar a produtividade e reduzir os seus custos (BALDWIN e CLARK, 1997). A estrutura modular na produção simplifica a linha de montagem por meio de pré-montagens e pré-testes funcionais dos módulos. As principais vantagens da modularidade nesta área funcional são a diminuição da linha principal de montagem, melhoria do controle de qualidade, da ergonomia dos equipamentos e dos postos de trabalho (HELPER et al., 1999), redução do tempo de produção pelos módulos, pois podem ser fabricados e montados de forma independente (VELOSO e FIXSON, 2001) e redução de estoque (FREDRIKSSON, 2006b) pela sincronização da linha de montagem da montadora com seus fornecedores de módulos.

Um exemplo de aplicação da modularidade da produção é um caso clássico da literatura, relativo a fábrica de caminhões e ônibus da Volkswagen, localizada em Resende, no Estado do Rio de Janeiro, inaugurada em 1996 (RAMALHO e SANTANA, 2002; ARBIX e ZILBOVICIUS, 1997). A determinação dos componentes de cada módulo do caminhão, realizada pela engenharia de produto e manufatura desta empresa, foi baseada nos seguintes fatores (ANDO, 2004):

- Consideração de cada módulo como uma única unidade, independente umas das outras;

- As funções e parâmetros de cada módulo e suas interdependências;

- Arquitetura do produto, ou seja, as funções de cada módulo e suas interfaces;

- Agrupamento em um mesmo módulo componentes que demandam tecnologia de processo e de produto semelhantes, delegando ao fornecedor que melhor domina essa determinada tecnologia.

Outro aspecto relevante na modularidade de produção é a flexibilidade nas variáveis do produto, que pode ser conseguida através da combinação de diferentes módulos num produto plataforma (FREDRIKSSON, 2006a,b), reduzindo os custos da customização em massa (ARNHEITER e HARREN, 2005). Isso ocorre porque o acoplamento de diferentes módulos origina um produto diferente, adequado para a necessidade de cada consumidor. Além disso, um reduzido número de unidades (módulos) na linha de montagem permite minimizar o tempo entre o momento em que o pedido é feito e em que o produto está finalizado, adaptando a produção às eventuais flutuações do mercado.

O estudo comparativo entre a montagem modular e convencional permite a constatação das seguintes observações sobre a modularidade de produção (ARBIX e ZILBOVICIUS, 1997; BALDWIN e CLARK, 1997; VAN HOEK e WEKEN, 1998; FRIGANT e LUNG, 2002; GRAZIADIO, 2004):

- Diminuição drástica dos componentes avulsos manuseados;

- Otimização do custo de transporte de materiais e do estoque, reduzindo o espaço físico necessário e transações fiscais;

- Redução do lead time de montagem, pois simplifica e acelera a linha de produção;

- Diminuição do tempo de produção também devido à produção paralela de módulos, não realizada de modo seqüencial. 
Essas constatações são facilmente observadas e intrínsecas à arquitetura modular. Porém, os custos dependem não somente da forma de produção (convencional ou modular), como também das variações de mercado, questões de tributação, entre outros. Dessa forma, parece ainda não haver informações suficientes para concluir se a modularidade é uma forma eficaz de redução de custos no setor automotivo ou não. Trata-se de um fenômeno isomorfismo mimético, em que as empresas estão aplicando essa solução não pelos seus resultados, mas porque assim o fazem outras empresas nas mesmas condições (ZILBOVICIUS, 1999). No Brasil, é comum que as montadoras relacionem-se com os fornecedores em duas formas distintas de arranjos industriais: o consórcio modular e o condomínio industrial (SALERNO et al., 1998).

\subsubsection{Modularidade de Uso}

A modularidade de uso procura satisfazer às necessidades do usuário de maneira adequada e mantendo os custos viáveis. Na indústria automotiva, a modularidade aplicada neste âmbito não é tão explorada como a modularidade de produção (GRAZIADIO, 2004). É importante ressaltar que o objetivo da modularidade de produção é o de melhorar o desempenho e a eficiência da linha produtiva, mas nem sempre atende as exigências do consumidor. Por exemplo, um veículo de menor peso possível e melhor desempenho pode não ser aquilo que o consumidor final deseja, se esse projeto de produto emprega peças de alto custo de reposição (BALDWIN e CLARK, 1997).

Como a diferenciação do automóvel na linha final de montagem não justifica o aumento do custo de produção, as montadoras oferecem ao consumidor algumas possibilidades de personalizar os produtos com módulos opcionais (BALDWIN e CLARK, 2000; GU e SOSALE 1999), ou seja, os produtos são personalizados por pacote de opcionais escolhidos pelos clientes nas concessionárias (SCAVARDA et al., 2005).

\subsection{Aplicação da Modularidade no Setor Automotivo - Exemplos}

Em geral, os principais benefícios da adoção da modularidade são (BALDWIN E CLARK, 2000): simplificar o processo do projeto, aumentar a produtividade no projeto do produto, possibilitar a redução de custos devido ao uso de módulos comuns em produtos diferentes e ajudar na customização em massa, Buscando alcançar estes benefícios o setor automotivo adotou esta estratégia. Nesse contexto, o Quadro 1 apresenta alguns exemplos de aplicação da modularidade na indústria automobilística.

Quadro 1 - Aplicações da modularidade.

\begin{tabular}{|c|l|c|}
\hline Autor & \multicolumn{1}{|c|}{ Resumo do artigo } & Empresa \\
\hline $\begin{array}{c}\text { Salerno et al. } \\
\text { (2008) }\end{array}$ & $\begin{array}{l}|c| \\
\text { Os autores realizaram estudos sobre os 10 anos da aplicação da modularidade }\end{array}$ & VW \\
& no Brasil, mostrando os benefícios e limitações da modularidade na cadeia de \\
& $\begin{array}{l}\text { seus fornecedores, pois ela também envolve a divisão de riscos e e } \\
\text { responsabilidades e investimentos entre ambas as partes. Verificou-se que os } \\
\text { fornecedores de primeiro nível de módulos têm aumentado os lucros e sua }\end{array}$ & \\
\hline
\end{tabular}




\begin{tabular}{|c|c|c|}
\hline & $\begin{array}{l}\text { importância na cadeia de suprimentos, mas também tem acrescido as suas } \\
\text { responsabilidades. }\end{array}$ & \\
\hline $\begin{array}{l}\text { De Mello e } \\
\text { Marx (2007) }\end{array}$ & $\begin{array}{l}\text { Os autores realizaram estudos de casos na fábrica VW que produz o Fox e em } \\
\text { seus fornecedores dos módulos de assento e cockpit. Verificou-se que a VW } \\
\text { utiliza diferentes estratégias sobre a transferência de projetos para } \\
\text { fornecedores, sempre mantendo o controle de parte do projeto de cada peça } \\
\text { ou módulo, seja definindo as especificações de projeto, seja transferindo } \\
\text { apenas o projeto de fabricação e montagem. Segundo os autores o uso da } \\
\text { modularidade tem gerado redução de custos devido a melhoria da logística e } \\
\text { ganhos de produção. }\end{array}$ & VW \\
\hline $\begin{array}{l}\text { Scavarda e } \\
\text { Barbosa } \\
(2005)\end{array}$ & $\begin{array}{l}\text { Os pesquisadores fizeram uma comparação de empresas automotivas } \\
\text { instaladas no Brasil com os resultados de um estudo europeu sobre as } \\
\text { empresas daqueles países. Verificaram que a estratégia do produto plataforma } \\
\text { tem sido aplicada e que o GM Celta foi desenvolvida com estratégia modular } \\
\text { no projeto e processo. Os resultados indicam o uso da estratégia de plataforma } \\
\text { com pacote de opcionais aplicados nas concessionárias (configuração tardia) } \\
\text { para personalizar o produto. }\end{array}$ & GM \\
\hline $\begin{array}{l}\text { Muffatto e } \\
\text { Roveda } \\
(2000)\end{array}$ & $\begin{array}{l}\text { Os autores realizaram três estudos de caso sobre a implantação de produtos } \\
\text { do tipo plataforma, sendo duas no setor automotivo. Verificou-se que produtos } \\
\text { modulares aumentam a flexibilidade por aumentar a variações de produtos. }\end{array}$ & $\begin{array}{l}\text { Carmake e } \\
\text { Scrapers } \\
\text { Co. linha } \\
\text { branca }\end{array}$ \\
\hline $\begin{array}{l}\text { Van Hoek e } \\
\text { Weken } \\
\text { (1998) }\end{array}$ & $\begin{array}{l}\text { Os autores realizaram um estudo de caso no projeto modular do "SMART car". } \\
\text { No projeto do carro a modularidade tem reduzido o lead-time da linha de } \\
\text { montagem, aumentando a flexibilidade desta linha, já que os módulos podem } \\
\text { ser combinados para formar diferentes produtos. Os módulos são fornecidos } \\
\text { em seqüência na linha de montagem. }\end{array}$ & $\begin{array}{l}\text { Parceria } \\
\text { Swatch e a } \\
\text { Mercedes- } \\
\quad \text { Benz }\end{array}$ \\
\hline Pires (1998) & $\begin{array}{l}\text { O autor apresentou o início do consórcio modular na VW. Nesse caso toda a } \\
\text { linha de montagem e sub-montagem são realizadas por } 7 \text { fornecedores. Para a } \\
\text { VW o consórcio modular reduziu o número de fornecedores, com expectativa } \\
\text { de reduzir os custos e o tempo de montagem. Para os fornecedores é uma } \\
\text { oportunidade de desenvolver novas competências, aumentar a parceria com a } \\
\text { VW e ter exclusividade de fornecimento. }\end{array}$ & VW \\
\hline
\end{tabular}

\subsection{Identificação e Análise de Trabalhos Sobre a Modularidade no Setor Automotivo}

Na busca bibliográfica inicial, foram identificados 105 trabalhos relacionados à modularidade. Desses trabalhos, alguns citavam a modularidade associada à construção civil, desenvolvimento de software ou gestão administrativa em módulo, portanto, fora do escopo do atual estudo. Assim, este número foi reduzido para 68 trabalhos analisados, sendo que 27 trabalhos são referentes ao setor automotivo. A seguir, é então apresentada uma bibliometria preliminar sobre estas publicações.

A Figura 1 apresenta a distribuição percentual do número de publicações por ano. Verifica-se nesta figura uma flutuação nos números de publicações entre os anos de 1998 a 2002, com forte queda no ano de 2003, enquanto que nos anos de 2004 a 2005 e 2007 apresentaram crescimento de publicações. Os dois periódicos que mais tem publicações neste tema são: Industrial Robot: An International Journal e o International Journal of Automotive Technology and Management (cada um com mais de $8 \%$ ). Verificou-se uma grande dispersão em relação às publicações sobre o tema já que foram identificados 68 artigos em 41 diferentes periódicos. 


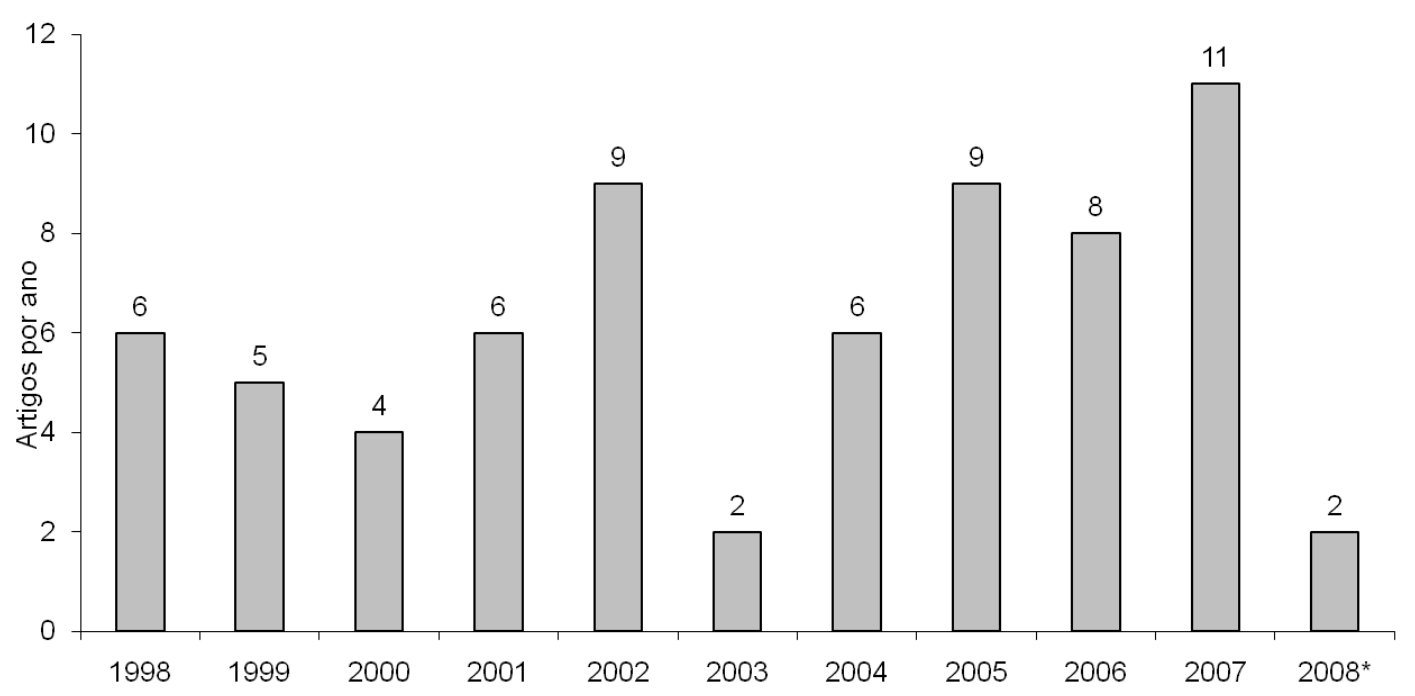

Figura 1 - Distribuição percentual do número de publicações por ano ("${ }^{*}$ parte de 2008).

Dos 68 artigos analisados sobre a modularidade, verifica-se que mais da metade dos casos são empíricos e pouco mais de $48 \%$ são conceituais. Isto era esperado, pois apesar da teoria da modularidade em projeto ter surgido na década de 70, a sua aplicação em grande escala, fora do setor de informática, tem ocorrido mais recentemente. Este fato tem gerado grande interesse em realizar trabalhos de caráter conceitual, que buscam analisar ou propor técnicas de modularidade, assim como para trabalhos de natureza empírica, buscando verificar os efeitos práticos da utilização desta estratégia em diferentes setores industriais.

A Figura 2 classifica mais detalhadamente as pesquisas nos seguintes grupos: "modelagem"; "teórico-conceitual"; "revisão de literatura"; "simulação"; "survey"; "estudo de caso"; "pesquisa-ação"; e (pesquisa) "experimental" apresentando o percentual destes grupos para cada ano. Em alguns casos, os artigos de foco "teórico-conceitual" também foram classificados como "estudo de caso" por realizarem testes da proposta desenvolvida em aplicações reais, como, por exemplo no trabalho de Assan et al. (2004). Em outras publicações, o trabalho envolvia a adoção de várias abordagens metodológicas, tais como "simulação" com dados coletados de um "estudo de caso", conforme o trabalho de Appelqvist e Gubi (2005). Verifica-se na Figura 2 que o estudo teórico conceitual tem se destacado nos anos de 1998 a 2001 como principal tipo de estudo realizado, enquanto que o estudo de caso destaca-se nos anos de 2004 a 2007. Aparentemente, existe uma tendência de crescimento dos trabalhos de campo sobre a modularidade a partir de 2004, deslocando o eixo de abordagem teórica para trabalhos de campo de natureza empírica. 


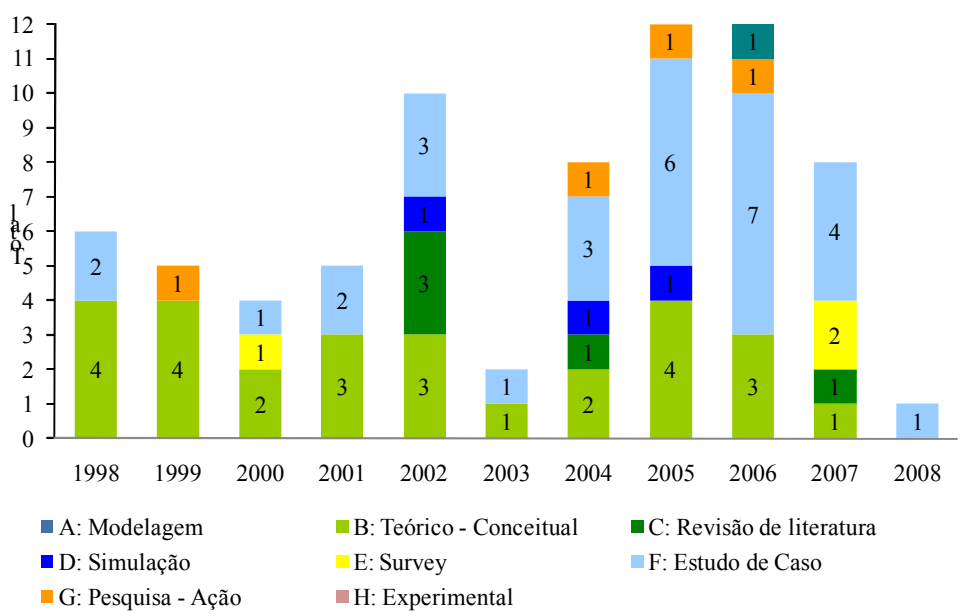

Figura 2 - Classificação por tipo de pesquisa

Sobre a classificação dos trabalhos em relação às abordagens "quantitativa" e "qualitativa", tem sido predominante a abordagem qualitativa totalizando mais de $61 \%$ dos casos classificados, com exceção dos anos de 2000, 2005 e 2007 quando a abordagem quantitativa predominou. O ano de 1999 apresenta os mesmos percentuais nas abordagens de natureza quantitativa e qualitativa, como mostra a Figura 3.

a: Quantitativo $\quad$ b: Qualitativo

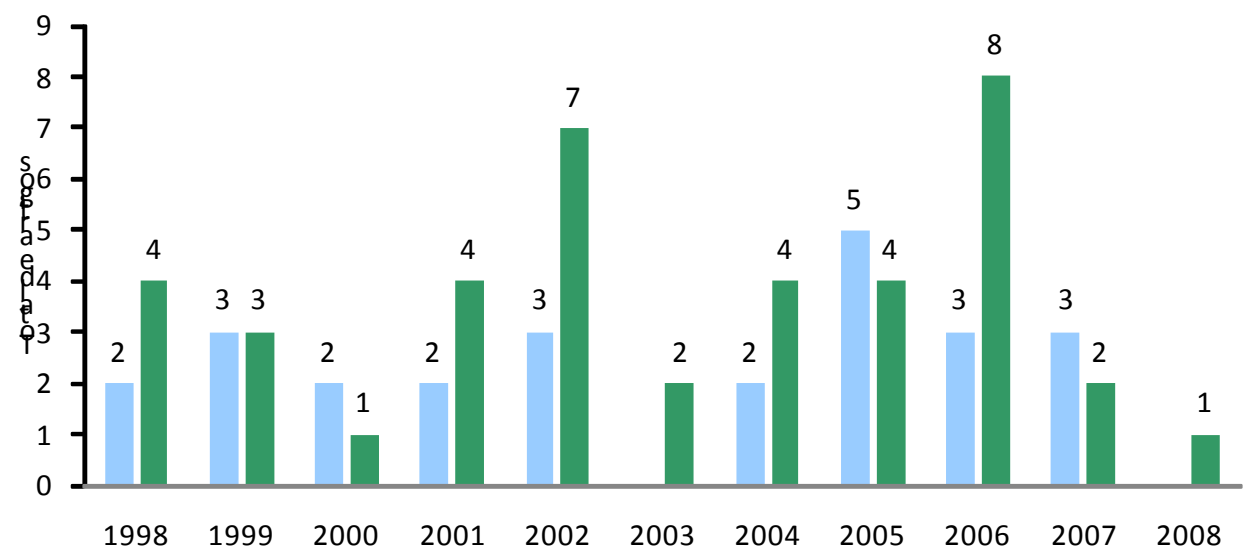

Figura 3 - Classificação por abordagem "quantitativa" e "qualitativa".

Sobre a abordagem de "estudo de caso", tem-se destacado os casos múltiplos, na grande maioria dos anos analisados (estudo de caso único com mais de $44 \%$ do total; estudo de casos múltiplos com mais de $55 \%$ ). Isto se deve a existência de um interesse acadêmico de não só verificar como a modularidade afeta a empresa que o aplica, mas também os seus efeitos na cadeia de fornecedores dessa empresa.

Dos 68 trabalhos analisados foi possível classificar em 65 deles o tipo de modularidade analisada ou aplicada em cada estudo (modularidade de projeto, produção, uso ou processo organizacional) sendo que 17 destes trabalhos foram 
classificados em mais de um tipo de modularidade. Verificou-se que, quando se compara pelo total de artigos analisados, a modularidade de produção destaca-se com $40 \%$ dos casos, a modularidade de projeto aparece com pouco mais de $27 \%$ dos trabalhos, a de processo organizacional com $20 \%$ dos trabalhos a qual está na maioria dos trabalhos diretamente relacionada com as alterações na cadeia de suprimentos geradas pela modularidade de produção. A modularidade de uso aparece com quase $13 \%$. Este resultado indica que a aplicação da modularidade está mais focada em melhorar o processo de montagem e fabricação das empresas. Uma análise por ano, apresentada na Figura 4, indica certa flutuação sendo que nos anos de 1998, 2000, 2002, 2006 e 2007 se destaca a modularidade de produção. Nos anos de 1999, 2001 e 2005 destaca-se a modularidade de projeto. Deste modo, a maioria dos estudos está voltada ao uso da estratégia modular mais centrada na perspectiva de projeto e ou de produção do produto.

Com o uso do diagrama de afinidades e do diagrama em árvore foi possível organizar de forma hierárquica em tabelas as informações sobre os benefícios e dificuldades do uso da modularidade considerando os 68 artigos analisados. Além disso, utilizou-se os diagramas também para especificar sobre os benefícios e dificuldades relacionadas aos 27 trabalhos sobre o setor automotivo.

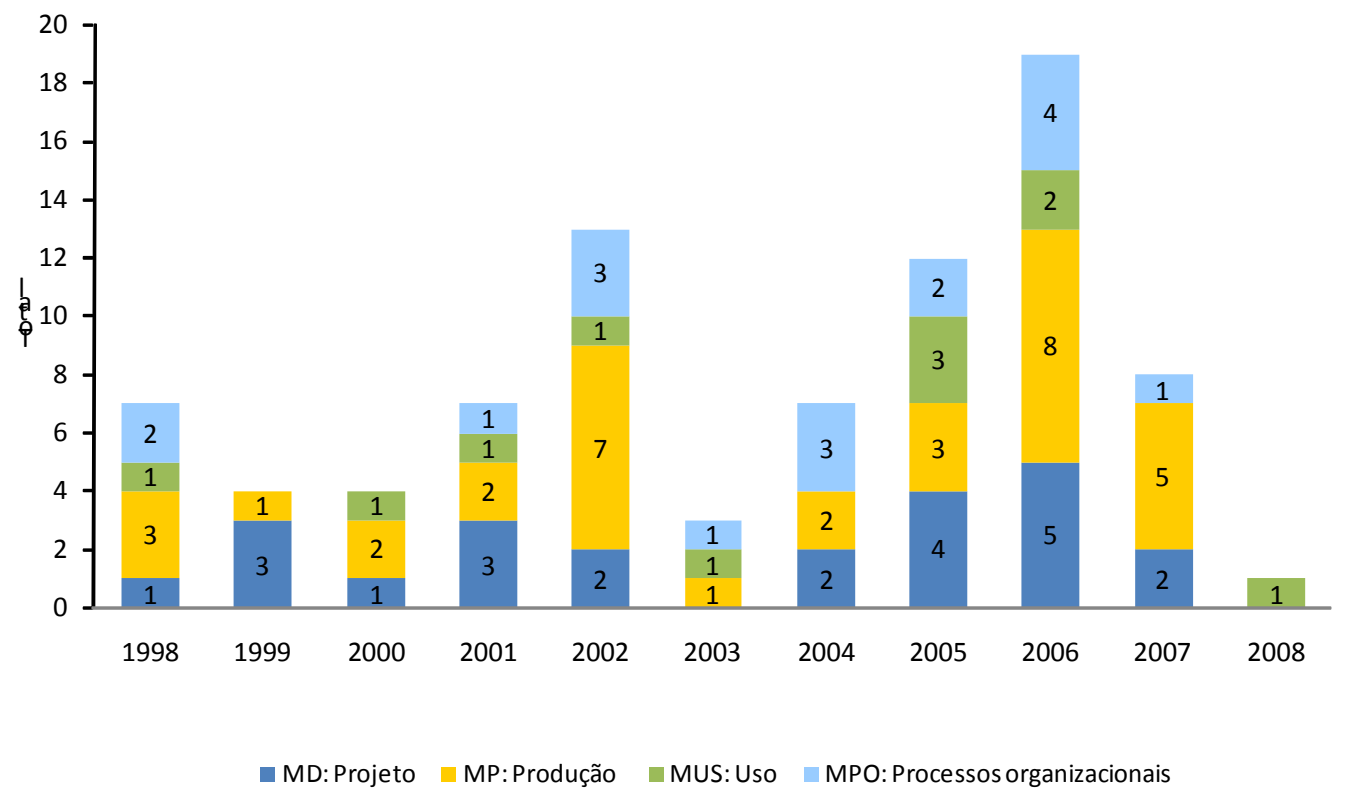

Figura 4 - Classificação por tipo de modularidade.

\subsubsection{Benefícios e Dificuldades na Adoção da Modularidade}

Sobre os benefícios gerais do uso da modularidade (análise de 68 artigos sendo identificadas 176 citações), verificou-se que os benefícios tangíveis se destacam com mais de $70 \%$ do total das citações. Estes benefícios estão relacionados principalmente ao aumento da flexibilidade da produção (VAN HOEK e WEKEN, 1988; CONNOLLY, 2007), melhoria da produtividade (SPATH e BAUMEISTER, 2001; ARNHEITER e HARREN, 2005), redução do tempo de desenvolvimento de produto (FRIGANT e LUNG, 2002; ARNHEITER e HARREN, 2005), e redução de custos (ZHANG et al., 2002). 
Os benefícios intangíveis foram citados em menor quantidade (em torno de $30 \%$ do total das citações) destacando-se a melhoria do serviço pós-venda, aumento da parceria com a montadora (ARNHEITER e HARREN, 2005), melhoria da qualidade (PIRES, 2002; FREDRIKSSON, 2006a), dentre outros.

Considerando apenas as 27 publicações do setor automotivo (total de 82 citações de benefícios) é possível fazer uma análise mais detalhada sobre os benefícios que a modularidade gera para as montadoras e para os fornecedores (autopeças). Com esta análise verificou-se que, do total de benefícios citados, mais de $84 \%$ são tangíveis sendo que pouco mais de $75 \%$ são relacionados à montadora e apenas pouco mais de $8 \%$ aos fornecedores. Deste modo, os resultados indicam uma tendência da montadora ser a grande beneficiada pela adoção da modularidade.

Para as montadoras automotivas, os principais benefícios tangíveis são:

- Aumento da flexibilidade da produção (VAN HOEK e WEKEN, 1998; PÉREZ e SANCHEZ, 2000; SANCHEZ e COLLINS, 2001; FREDRIKSSON, 2006a): por exemplo, aumentou a variedade de produtos por combinação de módulos;

- Redução do tempo de desenvolvimento (SANCHEZ e COLLINS, 2001; ARNHEITER e HARREN, 2005; PERSSON, 2006). Isto porque os módulos podem ser projetados de forma independente (VELOSO e FIXSON, 2001);

- Melhoria da produtividade (PIRES, 1998; VELOSO e FIXSON, 2001; ARNHEITER e HARREN, 2005; DE MELLO e MARX, 2007). Devido ao fato de que os módulos podem ser fabricados de forma independente (VELOSO e FIXSON, 2001);

- Redução dos custos de produção. Por exemplo, por reduzir a mão-de-obra direta na linha de montagem da montadora (PIRES, 1998; ARNHEITER e HARREN, 2005) e redução dos custos de montagem porque os fornecedores realizam as montagens dos módulos (FREDRIKSSON, 2006a);

- Redução dos custos de projeto de produto (SANCHEZ e COLLINS, 2001; ARNHEITER e HARREN, 2005; PERSSON, 2006).

Para os fornecedores, os benefícios tangíveis da modularidade estão na definição de contratos de longo período com a montadora (PIRES, 1998; ARNHEITER e HARREN, 2005), ter exclusividade para a fabricação e entrega dos módulos para a montadora (PIRES, 1998; FRIGANT e LUNG, 2002) e nos casos do fornecedor de primeiro nível da cadeia de suprimentos. Quando existe transferência de atividades para os fornecedores das empresas do primeiro nível na cadeia de suprimentos, a modularidade também pode gerar a redução do tempo de desenvolvimento e de entrega neste fornecedor (DORAN et al., 2007).

Os benefícios intangíveis correspondem a mais de $15 \%$ do total de benefícios citados, sendo que tem ocorrido na mesma proporção para as montadoras ( $6 \%$ dos benefícios citados) como para os fornecedores (também 6\% dos citados), e em mais de $3 \%$ são gerais para os dois casos, como por exemplo, tem correlação positiva com a utilização de equipes de trabalho (PÉREZ e SANCHEZ, 2000). Como exemplo de benefício intangível na montadora pode-se destacar a redução da complexidade do produto (VELOSO e FIXSON, 2001) e o auxilio na atualização da tecnologia do uso de plataforma na modularidade (PERSSON, 2006). Como exemplo de benefício intangível nos fornecedores, destacam-se os casos em que aumentou a parceria com a montadora (ARNHEITER e HARREN, 2005) e criação de oportunidade de desenvolver novas competências, tecnologia, processos no consórcio modular (PIRES, 1998). 
Sobre as dificuldades de utilização da modularidade, identificadas na análise dos 68 artigos (total 110 citações sobre as dificuldades), destacam-se as dificuldades relacionadas com a cadeia de suprimentos (com mais de $25 \%$ das citações) devido às alterações de uma cadeia de suprimentos tradicional, para uma que forneça produtos modulares (VAN HOEK e WEKEN, 1998; DORAN, 2005) e de atender a montadora de forma sincronizada (FREDRIKSOON, 2006a); risco pela transferência de atividades da montadora para os fornecedores (mais de $23 \%$ das citações), gerando dependência da montadora dos seus fornecedores de módulos (GADDE e JELLBO, 2002); necessidade de investimentos (mais de $22 \%$ das citações), como por exemplo, no investimento requerido para capacitar os fornecedores a fabricar os módulos (DORAN, 2002; ARNHEITER e HARREN, 2005); e aumento de custos para os fornecedores (mais de $9 \%$ das citações).

Sobre as dificuldades citadas anteriormente, apenas nos 27 artigos (total de 68 citações de dificuldades) referentes ao setor automotivo verifica-se que apenas mais de $35 \%$ das citações estão relacionadas às dificuldades do uso da modularidade pela montadora, contra mais de $64 \%$ relacionadas aos fornecedores indicando que a modularidade pode ter forte impacto nos fornecedores de primeiro nível da cadeia de suprimentos, que são os que vão fornecer os módulos para a montadora.

Para as montadoras as principais dificuldades estão relacionadas a:

- Transferência de atividades para seus fornecedores tais como: dificuldade de encontrar fornecedores capacitados para fabricarem os módulos, risco de perda de controle de alguns projetos (ARNHEITER e HARREN, 2005), dispersão das atividades e recursos (FREDRIKSSON, 2006a), e limitação do projeto dos módulos à capacidade atual dos fornecedores em fabricá-los (SANCHEZ e COLLINS, 2001);

- Gerir a linha de montagem da montadora: dificuldade de realizar o balanceamento da linha de montagem, pois os diferentes módulos têm tempo de montagens diferentes (FREDRIKSSON, 2006a) e lidar com o aumento do risco da linha parar se houver falhas de qualidade ou de entrega dos módulos pelos fornecedores (LARSSON, 2002; FREDRIKSSON, 2006a; 2006c).

Para os fornecedores, a aplicação da modularidade aumenta a sua dependência em relação às decisões tomadas pela montadora que o fornecedor atende (VAN HOEK e WEKEN, 1998; HOLMES, 2004). Além disso, as maiores dificuldades enfrentadas por estas empresas estão relacionadas com a necessidade de investimento para estar capacitada para fornecer os módulos (PIRES, 1998; DORAN, 2002; ARNHEITER e HARREN, 2005) em mais de $20 \%$ das citações, como por exemplo, investir na contratação de mão de obra para a montagem dos módulos (ARNHEITER e HARREN, 2005) e a necessidade de se fazer alterações na cadeia de suprimentos, com mais de $29 \%$ das citações (PIRES, 1998; DORAN, 2005) tais como:

- Necessidade de transferir as operações não importantes para fornecedores de segundo e terceiro nível da cadeia de suprimentos (GADDE e JELLBO, 2002);

- Ter produção JIT (Just in Time) ou sincronizada (DORAN, 2004) e, em alguns casos, de necessidade de até estar localizada próximo da montadora para facilitar a entrega dos módulos (FRIGANT e LUNG, 2002; DORAN, 2005; FREDRIKSSON, 2006c);

- Ter habilidade de entregar módulos na linha de produção da montadora (DORAN, 2004);

- Necessidade de ter operações flexíveis à variação de demanda (DORAN, 2003). 
Deste modo, observa-se que a maioria dos benefícios da aplicação da estratégia modular tende a favorecer as empresas montadoras, enquanto que a maioria das dificuldades de aplicação tem atingido os fornecedores dessas montadoras.

\subsection{Síntese dos Resultados da Literatura}

Apesar de este trabalho apresentar alguns resultados da revisão de literatura sobre a modularidade, já é possível verificar algumas tendências e conclusões iniciais sobre os dados analisados. Primeiramente, verifica-se uma grande dispersão de publicações sobre o assunto, existindo poucos periódicos que publicaram mais de um trabalho nos últimos 10 anos. Verificou-se uma aparente mudança de foco dos estudos analisados neste período. Até o ano de 2003, os trabalhos eram mais voltados para estudos conceituais focados no desenvolvimento da teoria de aplicação da modularidade, enquanto que a partir de 2004 o foco da maioria dos estudos alterou-se para trabalhos empíricos envolvendo estudo de casos múltiplos e pesquisa-ação, buscando investigar os efeitos da modularidade nas empresas que as aplicam e nos seus fornecedores.

Sobre o tipo de modularidade utilizado, tem-se destacado a modularidade de produção indicando um forte interesse das empresas em melhorar aspectos da flexibilidade, produtividade e redução dos custos de produção. Em relação aos benefícios da sua utilização, estes são, na sua maioria, tangíveis, o que pode permitir o desenvolvimento futuro de propostas para avaliar os benefícios econômicos do uso da estratégia modular.

A análise dos dados exclusivos do setor automotivo deixa claro que os seguintes aspectos devem ser investigados em maior profundidade: os resultados indicam que as montadoras são as grandes beneficiadas pelo uso da modularidade; a maioria destes benefícios é causada pela transferência de atividades e responsabilidades da montadora para os seus fornecedores. Aparentemente, os fornecedores são os que desempenham o maior esforço para se adaptar à estratégia modular, ou seja, são os que enfrentam as maiores dificuldades na sua aplicação.

\section{ABORDAGEM METODOLÓGICA DE PESQUISA}

A caracterização metodológica do presente trabalho é predominantemente de natureza empírica, cujo trabalho de campo é realizado por meio da abordagem de estudo de caso, de acordo com a literatura (YIN, 2001; VOSS et al., 2002), utilizando como técnica para a coleta de dados entrevistas semi-estruturadas (MARCONI e LAKATOS, 1996).

\subsection{Levantamento de Campo}

O presente trabalho origina-se de um projeto de pesquisa que investiga, em linhas gerais, a adoção da modularidade no setor automotivo. $O$ presente trabalho 
foca na análise geral de como as iniciativas associadas à modularidade são adotadas por uma montadora automotiva. Mais especificamente, busca responder a seguinte questão geral de pesquisa: como a modularidade é adotada e quais são as suas práticas organizacionais associadas a esta adoção? A partir da questão geral de pesquisa, foram verificadas e analisadas no presente estudo as seguintes variáveis qualitativas: projeto modular, cooperação com os fornecedores no desenvolvimento de novos produtos, transferência de atividades para os fornecedores, benefícios e dificuldades na adoção da modularidade, e organização dos fornecedores em um condomínio modular. Os resultados são estruturados e apresentados segundo estas variáveis, que são ligadas a questão geral de pesquisa. O trabalho de campo foi realizado em uma empresa montadora de veículos e busca associar os dados coletados com estudos similares da literatura, destacando-se o trabalho de De Mello e Marx (2007), Doran et al. (2007) e Fredriksson, (2006a, 2006b, 2006c).

No que tange a base metodológica, inicialmente foi realizado um levantamento da literatura, no qual delineou-se os pontos importantes sobre modularidade e, posteriormente, relacionou aos temas de interesse para o presente estudo destacado no item anterior. A seguir, escolheu-se o método de estudo de caso como abordagem de pesquisa por considerá-lo como mais adequado face a questão de pesquisa e natureza (qualitativa) dos dados a serem coletados e analisados. O estudo de caso se caracteriza como uma estratégia de pesquisa adequada quando as questões de interesse referem-se ao "como" e ao "por que" e/ou quando o pesquisador tem pouco controle sobre os acontecimentos e o foco se dirige a um fenômeno contemporâneo em um contexto natural (YIN, 2001). O trabalho é de natureza exploratória, pois a literatura é relativamente limitada no foco escolhido, seja pelo tema "modularidade no processo de desenvolvimento de produtos" estar em fase inicial, principalmente quanto a abordagem empírica (CAMUFFO, 2000; DORAN, 2003).

Para coleta de dados, foi realizada uma entrevista semi-estruturada com o responsável pelo desenvolvimento de novos produtos de uma das plantas da montadora estudada, com uma duração de aproximadamente três horas. O conteúdo foi gravado, transcrito, e posteriormente enviado ao entrevistado para possíveis ajustes nas informações, quanto a precisão e sigilo dos dados, buscando uma validação da narrativa. Ainda na entrevista, foi feita uma apresentação, feita prelo entrevistado, que auxiliou no entendimento dos aspectos relativos ao processo de desenvolvimento de módulos e algumas decorrências organizacionais, associadas aos fornecedores.

Os motivos da escolha da montadora estudada são baseados ao fato da mesma ter, atualmente, certa autonomia local para desenvolvimento de novos produtos (automóveis), ter um relacionamento próximo com os fornecedores no desenvolvimento de componentes, além de ter sido obtido acesso para a coleta de dados. Além disso, existem muitas interfaces de montagem na planta estudada e algumas indicações na literatura sobre a adoção do conceito de modularidade nessa montadora de veículos. 


\subsection{Contexto do Trabalho de Pesquisa e Perfil da Unidade de Análise}

O trabalho de campo foi realizado em uma multinacional montadora de veículos que, segundo os dados da ANFAVEA (Associação Nacional dos Fabricantes de Veículos Automotores), está entre as quatro empresas que tiveram a maior quantidade de automóveis licenciados nos meses de janeiro e fevereiro de 2009. Tal empresa tem várias plantas industriais no país.

Para a coleta de dados foi entrevistado um engenheiro sênior envolvido com o desenvolvimento de uma plataforma no final da década de 90 para ser fabricado numa planta do condomínio modular. Uma plataforma é um conjunto de componentes, sistemas ou subsistemas que são iguais numa família de produtos (ROZENFELD et al., 2006). Os dois veículos desenvolvidos com esta plataforma são modulares. Segundo o entrevistado, o desenvolvimento desta plataforma foi principalmente realizado na matriz da empresa fora do país.

Tal projeto foi também utilizado para o desenvolvimento do know how e para a capacitação da equipe de engenharia brasileira, a qual teve grande parte dos seus membros acompanhando todo o desenvolvimento na matriz. Como já apontado pela literatura (e.g. SALERNO, 2001), até o final da década de 90 as equipes de projeto do produto do Brasil estavam restritas em realizar uma tropicalização de produtos desenvolvidos fora do país (na matriz ou em outras subsidiárias), adaptando a produção inicialmente para montar os veículos com os componentes importados e posteriormente desenvolvendo o ferramental e os fornecedores locais para fabricar os componentes no Brasil. Essas equipes também realizavam pesquisa de mercado, para verificar a viabilidade do desenvolvimento de novos veículos, identificando seus requisitos, mas limitados a esta atividade. Embora essa informação não seja recente, isto é corroborado por Rozenfeld et al. (2006), que afirmam que nos países em desenvolvimento normalmente os produtos são trazidos externamente das matrizes onde o projeto foi desenvolvido. Assim, geralmente, a montadora fica restrita em adaptar o produto ao mercado local, aos fornecedores e aos processos de manufatura existentes no país, como o que ainda vem ocorrendo nas montadoras de origem francesa, instaladas no Brasil.

Após o desenvolvimento desse projeto plataforma houve certa descentralização da matriz no desenvolvimento de novos produtos em relação a planta brasileira ao desenvolver uma equipe nacional capacitada, que desenvolve atualmente projetos de veículos parcial ou, com certas restrições, totalmente nacionais. Como por exemplo, pode-se citar a criação de um veículo sedan a partir de um veículo hatch ou o reprojeto de uma nova versão de um veículo existente, aproveitando o ferramental existente, adaptando chassis e projetando uma nova carroceria para o veículo. A apresentação dos resultados mais detalhados é feita a seguir.

\section{RESULTADOS E DISCUSSÃO}

Os resultados são subdivididos de acordo com as variáveis analisadas, a saber: a adoção do projeto modular, a cooperação com os fornecedores no desenvolvimento de produto, a transferência de atividades para os fornecedores, os benefícios e dificuldades associadas à adoção da modularidade na empresa 
estudada e, finalmente, a organização dos fornecedores em um condomínio modular.

\subsection{A Adoção do Projeto Modular}

De acordo com os dados coletados, os dois veículos resultantes da plataforma desenvolvida apresentam os seguintes módulos: "motor e transmissão"; "carroceria estrutural"; "painel de instrumentos"; "porta"; "bancos"; "chassi"; "sistema de escapamento"; "suspensão dianteira" e módulo da "suspensão traseira". Uma divisão similar do veículo em módulos é encontrada nos modelos Golf, Polo da WW que também apresentam os módulos similares "painel de instrumentos"; "porta"; "bancos"; "suspensão dianteira" e o módulo "suspensão traseira", como aponta a literatura (DE MELLO e MARX, 2007). Entretanto, existem algumas diferenças ou módulos que não foram citados, por exemplo no caso da VW não é citada a existência do módulo "carroceria estrutural" e o módulo "motor e transmissão", mas sim o módulo "front-end" (envolvendo toda a parte frontal do veículo) e o módulo "tanque de combustível". Por outro lado, Pandremenos et al. (2009) recomendam uma divisão um pouco diferente do veículo em cinco grandes subconjuntos: "frontend" (envolvendo toda a parte da frente do veículo), "assoalho" (envolvendo também os bancos); "teto"; "upper body" (desde as portas e parte interna do veículo); "rearend" (desde o porta malas até o para choque). Assim, verifica-se que os módulos variam conforme a lógica de divisão e agrupamento utilizado pela montadora, de certo modo seguindo a lógica de divisão funcional apontada na literatura (FIXON, 2005; BI e ZHANG, 2001).

Sobre como os módulos foram definidos, os dados coletados não permitiram fazer esta avaliação com precisão. No entanto, o entrevistado defendeu que foi levado em conta o processo de montagem a partir de três grandes sistemas do veículo: "sistema de propulsão" (módulo do motor e transmissão); "chassi" (módulo chassi; sistema de escapamento; suspensão dianteira; suspensão traseira, incluindo rodas e pneus); e "carroceria" (carroceria estrutural, painel de instrumentos, porta e bancos). A literatura define a modularidade com base no cliente (CAUCHICK MIGUEL e PIRES, 2006), nas funções do produto (SHIBATA et al., 2008; CONNOLLY, 2007; DAHMUS et al., 2001; GADDE e JELLBO, 2002) ou na estrutura do produto (ASAN et al., 2004). No caso publicado da VW, também foram considerados a produtividade e aspectos ergonômicos da linha de montagem de veículos (De Mello e Marx, 2007), o que é similar à recomendação de Pandremenos et al. (2009) ao definir-se a quantidade de módulos considerando então os requisitos de montagem. Assim, os resultados obtidos parecem estar alinhados à literatura, pois os módulos definidos na montadora estudada apresentam aspectos de função do produto, além de considerar requisitos de montagem.

Sobre quem define os requisitos dos usuários a serem atendidos e a especificação de projeto do produto verificou-se que este processo é realizado pela montadora, que utiliza para isso uma matriz do desdobramento da função qualidade (QFD), além de um banco de dados que contém o know how da empresa sobre o produto. O uso do método QFD no setor automobilístico para identificar os requisitos dos clientes e desdobrá-los em especificações de produto também pode ser visto na Ford Motor Company na Europa (AL-MASHARI et al., 2005), na VW ônibus 
(FRAGOSO, 1999), na Volvo (EKDAHL e GUSTAFSSON, 1997), dentre outras empresas do setor automotivo.

\subsection{A Cooperação com os Fornecedores no Desenvolvimento de Produto}

Em relação aos projetos de desenvolvimento dos módulos, os dados coletados indicam que eles podem ser de três tipos:

- Projeto realizado somente pela montadora: normalmente envolvendo o desenho completo do veículo, os módulos: motor e transmissão, carroceria estrutural e parte do módulo da porta (parte estampada);

- Projeto em conjunto com os fornecedores: em alguns casos o projeto do módulo ou de seus componentes é realizado por equipes mistas com engenheiros da montadora e dos fornecedores. Por exemplo, alguns dos módulos que formam o chassi são desenhados em conjunto (engenheiros da montadora e dos fornecedores). Além disso, alguns subconjuntos dos módulos também envolvem projetos com equipes mistas entre a montadora e fornecedores de primeiro e segundo níveis da cadeia de suprimentos, o que indica certa transferência de atividades e de know how entre as empresas, também apontado pela literatura (FREDRIKSSON, 2006b; LAU e YAM, 2005).

- Projeto desenvolvido pelo fornecedor: nestes casos alguns módulos e subconjuntos, tais como: bancos, painel de instrumento e direção são desenvolvidos pelos fornecedores, sendo que todos os requisitos de projeto, de performance e de design são definidos pela montadora. Entretanto, não são necessariamente projetos do tipo "caixa-preta" como citado no caso da VW (em DE MELLO e MARX, 2007). Isto pode ser explicado pelo fato de que existe uma maior interação, troca de informações e, algumas vezes, até definição de alguns materiais em conjunto pelas empresas. Apesar disso, o projeto detalhado e o processo de fabricação fica sob a responsabilidade do fornecedor.

Esses tipos de projetos apresentam algumas semelhanças com os quatro tipos de estratégias utilizadas pela Volkwagem Automóveis no desenvolvimento dos módulos do painel de instrumentos e dos bancos do Fox no Brasil. Essas estratégias são (DE MELLO e MARX, 2007): "caixa preta" (onde a VW fornece todos os requisitos "book of work statement" para os fornecedores que desenvolvem o projeto); co-design (realizado em conjunto com a VW), similar ao que ocorre na empresa estudada; desenvolvimento de ferramental (o fornecedor desenvolve o ferramental e o processo de fabricação) e também o planejamento do processo de fabricação (o fornecedor desenvolve o processo de fabricação e a VW as peças e o ferramental). No entanto, no caso da VW, verifica-se uma participação maior da montadora nos projetos dos módulos bancos e painel de instrumentos, quando comparado com a empresa estudada, seja pela VW realizar co-design de vários subconjuntos dos módulos ou por realizar parte do desenvolvimento do ferramental que fabricará os módulos. Deste modo, os projetos tipo "caixa preta" estão limitados a apenas subconjuntos dos dois módulos citados e não o módulo em si. 


\subsection{Transferência de Atividades para os Fornecedores}

Segundo os dados coletados, os módulos desenvolvidos pelos fornecedores em conjunto ou não com a montadora são fabricados e montados por esses fornecedores os quais devem ser entregues na linha de montagem final da montadora. Deste modo, existe uma transferência das atividades de submontagem da montadora para o fornecedor de primeiro nível, em concordância com o que indica a literatura (VELOSO e FIXSON, 2001; FREDRIKSSON, 2006a; DE MELLO e MARX, 2007; ORSATO e WELLS, 2007). Também ocorre a transferência de parte das atividades de projeto, o que também é citado na literatura (LAU e YAM, 2005; FREDRIKSSON, 2006c; DE MELLO e MARX, 2007). O fornecedor de primeiro nível também ficou responsável por relacionar-se com a maioria dos fornecedores dos níveis subsequentes da cadeia de suprimentos (segundo e terceiro níveis), como aponta a literatura (LAU e YAM, 2005; DORAN et al., 2007), inclusive no desenvolvimento do projeto, sendo responsável por gerir os estoques referentes aos módulos, com exceção dos componentes fabricados na montadora.

\subsection{Benefícios da Modularidade na Empresa Estudada}

Sobre quais são os benefícios para a montadora do uso de módulos montados pelos fornecedores foram indicados:

- A diminuição do número de testes, pois realiza o teste do módulo ao invés de testar cada componente que o compõe em separado, ou seja, facilita a inspeção do produto, corroborado por Chen et al. (2006);

- A redução do número de engenheiros na montadora para desenvolver todo o produto, pois parte do projeto é desenvolvido no fornecedor, ou seja, reduz os recursos necessários para desenvolver o projeto, conforme demonstrado na literatura (PERSSON, 2006; ARNHEITER e HARREN, 2005; FRIGANT e LUNG, 2002; SANCHEZ e COLLINS, 2001). Esses recursos estão relacionados aos custos fixos gerados para ampliar a estrutura necessária, para manter uma maior equipe de projeto trabalhando dentro da fábrica, como ampliação do prédio da empresa. Entretanto, os custos de desenvolvimento do projeto, pelo fornecedor, são repassados para a montadora, inseridos no custo dos módulos, o que pode indicar que não existe uma grande redução de custos;

- O aumento da parceria entre a montadora e o fornecedor pela participação dos fornecedores no desenvolvimento de novos produtos com a montadora, nos projetos em conjunto, como já identificado por Silva e Rozenfeld (2007);

- A possibilidade de que alguns módulos sejam desenvolvidos em paralelo o que pode reduzir o tempo de desenvolvimento (conforme VELOSO e FIXSON, 2001), apesar de que essa redução não foi quantificada na coleta de dados do presente trabalho;

- A redução do número de operários da linha de montagem e fabricação da montadora, por terceirizar a fabricação e a montagem da maioria dos módulos para os fornecedores o que é muito citado na literatura (ARNHEITER e HARREN, 2005; DORAN, 2002; PIRES, 2002; COLLINS et al., 1997);

- A possibilidade de que a engenharia da montadora focasse nos aspectos de desempenho e conforto do produto ao invés de detalhes do projeto e dos seus processos de fabricação que ficaram na sua grande maioria sob a responsabilidade dos fornecedores de primeiro nível. Segundo a literatura (COLLINS et al., 1997; MARX et al., 
1997), a montadora também poderia estar focada mais em outros aspectos, tais como: serviços pós-venda e "varejo e distribuição", mas estes aspectos não foram citados.

Deste modo, verifica-se que a aplicação da modularidade pela montadora estudada com a transferência de atividades para seus fornecedores geraram benefícios organizacionais, associados à redução de alguns custos fixos, os quais são transferidos para os fornecedores, embora os valores não tenham sido quantificados.

\subsection{Dificuldades Associadas a Adoção da Modularidade na Empresa Estudada}

Sobre as dificuldades do uso da modularidade foram levantadas:

- O aumento da dependência com relação os fornecedores o que dificulta a troca dos principais fornecedores dos módulos, fato presente na literatura (FRIGANT e LUNG, 2002; COLLINS et al., 1997);

- O aumento do trabalho gerencial na linha de produção, pois aumenta o número de itens a serem administrados na linha de montagem da montadora com necessidade de maior controle de inventário; pois têm que estar documentados todos os módulos, seus componentes, variações e para que veículo cada um se destina. Ou seja, gera um aumento da complexidade com o aumento do número de pacotes e de opcionais, como destacado por Scarvada et al. (2005);

- A existência de uma migração do conhecimento dos detalhes sobre o projeto do módulo, sobre o processo de fabricação e parte da estrutura do produto. Isto pode gerar dispersão das atividades e de recursos (FREDRIKSSON, 2006a) e aumento da interdependência entre as empresas (COLLINS et al., 1997);

- A criação de uma linha de montagem final modular, que demanda a necessidade de se fazer alterações na linha de produção, ou seja, gera-se uma necessidade de investimento na linha de produção. Na literatura verifica-se também que os fornecedores têm necessidade de investirem para estarem capacitados para fornecerem os módulos (ARNHEITER e HARREN, 2005; DORAN, 2002), não sendo assim uma dificuldade apenas da montadora;

- A inclusão dos custos dos projetos desenvolvidos pelos fornecedores, que são alocados nos custos dos módulos, ou seja, são pagos pela montadora.

Deste modo, no caso da empresa estudada, verifica-se que a modularidade aumenta a dependência entre as empresas, que a redução dos custos vai depender se o desenvolvimento do produto, fabricação e montagem for ou não mais barato de se realizar no fornecedor do que na montadora. Conclui-se que a aplicação da modularidade não é uma tarefa simples e que exige inclusive investimentos para modificar ou criar uma nova linha de montagem de veículos.

\subsection{Organização dos Fornecedores em um Condomínio Modular}

O entrevistado também forneceu dados sobre o condomínio modular onde os produtos do projeto plataforma desenvolvidos são fabricados. Após a construção da planta industrial, a empresa convidou seus principais fornecedores para instalaremse em área próxima à montadora. Para isto, a montadora forneceria o terreno em volta da sua planta, o qual continuaria sendo de sua propriedade, mas dando ao 
fornecedor autorização para ele construir o prédio que seria de propriedade do fornecedor. Em alguns casos, existiu até um apoio financeiro para o fornecedor instalar-se dentro no condomínio. Entretanto, nenhuma empresa foi obrigada a fazer tal mudança, ou seja, instalar-se nas proximidades, sendo que ainda hoje existem fornecedores desta planta, que continuam fora do condomínio. Apesar desse argumento, verificou-se durante a entrevista que, no caso de alguns fornecedores de componentes para os módulos (de segundo e terceiro níveis na cadeia de suprimentos), houve uma troca por fornecedores locais devido a facilitar os aspectos logísticos.

Segundo Larsson (2002) e Frigant e Lung (2002), a necessidade de entregar os módulos em seqüência e de forma sincronizada na planta da montadora é um dos principais motivos que tem incentivado os fornecedores de módulos a se instalarem próximos das plantas das montadoras, que eles atendem. Entretanto, para Salerno et al. (2008), o controle sobre o condomínio modular é todo da montadora, inclusive como será a divisão de investimento no condomínio e dos projetos em conjunto. Larsson (2002) identificou outras plantas de montadoras que apresentam algumas características similares com o condomínio modular estudado no Brasil, chamada pelo autor de parque de fornecedores, entre elas estão uma planta da Ford, uma planta da Audi na Alemanha, uma planta da SEAT na Espanha e uma planta da Volvo na Suécia. A principal característica desses parques de fornecedores é estarem próximos da montadora que eles atendem. Isto indica uma tendência estratégica não limitada à indústria automobilística no Brasil, já relativamente bem explorada na literatura. No condomínio modular, os fornecedores tem suas plantas vizinhas às da montadora e realizam a submontagem de módulos e subsistemas, enquanto que a montadora realiza a montagem final do produto. Neste caso, existe uma coordenação logística para garantir uma integração que seja econômica. Isto está de acordo com o presente estudo, pois a maioria dos fornecedores instalados no condomínio apenas monta os módulos e entregam na linha de montagem da montadora, que realiza a montagem final do veículo. Além disso, a maior parte dos estoques foi transferida da montadora para o fornecedor, ficando a montadora apenas com um estoque mínimo na planta.

Assim, verificou-se que o condomínio modular é uma maneira de criar uma forte parceria com vantagens logísticas, mas que ao mesmo tempo aumenta ainda mais a interdependência entre as empresas, vistas as dificuldades que pode gerar a troca de um dos fornecedores.

\section{CONCLUSÕES}

O presente trabalho identificou convergência dos resultados da empresa estudada com a literatura. Conclui-se que, na definição dos módulos, são considerados aspectos de função do produto e requisitos de montagem, na montadora investigada. No entanto, percebe-se que na literatura ainda não existe uma definição clara entre as montadoras sobre como a divisão dos módulos deve ser feita, ou seja, os módulos variam de acordo com a lógica de divisão e agrupamento utilizado por cada montadora (comparando os resultados de campo com a literatura). Em relação aos projetos de desenvolvimento de módulos, este é realizado de três modos na empresa analisada: somente pela montadora; em conjunto com os fornecedores; ou somente pelo fornecedor. De qualquer modo, 
sendo o módulo desenvolvido em conjunto ou não com a montadora, são os fornecedores que fabricam, montam, e entregam no final da linha de montagem da montadora.

$\mathrm{Na}$ investigação foram destacados alguns benefícios da utilização da modularidade, tais como: diminuição do número de testes de produtos; redução dos recursos para desenvolver projetos; aumento da parceria entre montadora e fornecedor; redução da quantidade de operários na linha de montagem e fabricação; e ainda permite um melhor foco dos engenheiros em aspectos de desempenho e conforto do produto. Em contra partida, com relação aos benefícios, enfatiza-se também algumas dificuldades, tais como: um aumento da dependência em relação aos fornecedores; aumento do trabalho administrativo na linha de produção; migração de conhecimentos dos projetos do módulo para o fornecedor; necessidade de investimentos para criar uma linha de montagem modular; e os custos do desenvolvimento de projetos pelo fornecedor são repassados à montadora no preço dos módulos. A partir do presente investigação, conclui-se que os benefícios são mais associados à montadora enquanto que as dificuldades são mais relacionadas aos fornecedores.

Finalizando, reforçar-se a conclusão de outros estudos que o condomínio modular estabelece uma parceria com vantagens logísticas, mas que ao mesmo tempo aumenta a dependência em relação aos fornecedores, gerando um trade-off que precisa ser melhor explorado. A partir deste estudo de caso e da análise da literatura sobre modularidade, observa-se que algumas implicações teóricas e empíricas ainda não estão bem definidas, embora este não seja um tema de pesquisa totalmente novo. Desta forma, algumas possibilidades para trabalhos futuros são identificadas, tais como uma análise mais aprofundada das variáveis investigadas na perspectiva do projeto modular, ou seja, a partir do desenvolvimento de um novo produto com arquitetura modular, quais são as conseqüências envolvidas para outros processos organizacionais, como os de produção, qualidade ou outros.

\section{REFERÊNCIAS}

ALLER, R. A. et al. New tendencies in inter-firm relations in the automotive industry and their impact on European periphery suppliers - lessons from Spain. European Urban and Regional Studies, v.6, n.3, 1999.

AL-MASHARI, M. et al. Key enablers for the effective implementation of QFD: a critical analysis. Industrial Management \& Data Systems v. 105, n. 9, p. 1245-1260, 2005.

ANDO, R. A. Modularidade e seus Impactos no Desenvolvimento de Novos Produtos e Processos na Indústria Automobilística, São Paulo, FEA USP, Departamento de Administração, Dissertação de Mestrado, 2004.

ANFAVEA Carta da ANFAVEA: Resultados de fevereiro e do primeiro bimestre de 2009. n. 274, Março, 2009. Disponivel em: < http://www.anfavea.com.br/cartas/carta274.pdf>. Acesso em 04 abril, 2009. 
APPELQVIST, P.; GUBI, E. Postponed variety creation: case study in consumer electronics retail. International Journal of Retail \& Distribution Management, v. 33, n. 10, p. 734-748, 2005.

ARBIX, G; ZILBOVICIUS, M. Local Adjustment to Globalization: a comparative study of foreign investment in two regions in Brazil, Greater $A B C$ and Greater Porto Alegre, International Labor Organization, 2000.

ARBIX, G.; ZILBOVICIUS, M. Consórcio Modular da VW: um novo modelo de produção? In: ARBIX, G.; ZILBOVICIUS, M. De JK a FHC: a reinvenção dos carros. São Paulo: Scritta, 1997.

ARNHEITER, E.D.; HARREN, H. Quality management in a modular world, v. 18, n. 1, p. 87-96, 2006.

ARNHEITER, E.D.; HARREN, H. A typology to unleash the potential of modularity. Journal of Manufacturing Technology Management, v. 16, n. 7, p. 699-711, 2005.

ASAN, U. et al. An integrated method for designing modular products. Journal of Manufacturing Technology Management, v. 15, n. 1, p. 29-49, 2004.

BALDWIN, C.Y.; CLARK K.B. Design Rules, MIT Press, Massachusetts, 2000.

BALDWIN, C.Y.; CLARK K.B. Managing in the Age of Modularity, Harvard Business Review, September-October, 1997.

BALDWIN, C.Y.; CLARK K.B. Modularity in the Design of Complex Engineering Systems http://www.people.hbs.edu/cbaldwin/DR2/BaldwinClarkCES.pdf 01/2004.

BI, Z.M.; ZHANG, W.J. Modularity technology in manufacturing: taxonomy and issues. The International Journal of Advanced Manufacturing Technology, v. 18, n. 5, p. 381-390, 2001.

CAMUFFO, A. Rolling out a World Car: Globalization, Outsourcing and Modularity in the Auto Industry, IMVP Working paper. 2000. Available: http://imvp.mit.edu.parpers.

CAUCHICK MIGUEL, P.A. Perspectivas e implicações da modularidade no desenvolvimento de produto - estudo bibliográfico inicial. Anais do Simpósio de Engenharia de Produção - SIMPEP, UNESP, Bauru, 2004.

CAUCHICK MIGUEL, P.A. Modularity in Product Development: A Literature Review Towards a Research Agenda. Product: Management and Development, v. 3, No. 2, pp. 165-174, 2005.

CAUCHICK MIGUEL, P.A. The potential of new product development in the automotive industry in Brazil: An exploratory study. Product: Management and Development, v. 4, n. 1, p. 35-43, 2006. 
CAUCHICK MIGUEL, P.A.; PIRES, S.R.I. A Case Study on Modularity in Product Development and Production within the Auto Industry. International Journal of Automotive Technology and Management, v. 6, p.315 - 330, 2006.

CEPOLINA, F.; MICHELINI, R.C. A family of co-robotic surgical set-ups. Industrial Robot: An International Journal, v. 30, n. 6, p. 564-574, 2003.

CHEN, C.H; et al. Tracking a moving object with real-time obstacle avoidance. Industrial Robot: An International Journal v. 33, n. 6, p. 460-468, 2006.

COLLINS, R. et al. Outsourcing in the automotive industry: from JIT to Modular Consortia. European Management Journal v. 15, n. 5, p. 498-508, 1997.

CONNOLLY, C. Robots at the heart of Schubert packaging machinery lead to great flexibility. Industrial Robot: An International Journal, v. 34, n. 4, p. 277-280, 2007.

CORREAA, H. L. Linking Flexibility, Uncertainty and Variability in Manufacturing Systems: managing un-planned change in the automotive industry. England, Avarbury, p. 198, 1994.

DAHMUS, J.B. et al. Modular product architecture. Design Studies, v. 22, n. 5, p. 409-424, 2001.

DE MELLO, A.M.; MARX, R. Innovative capacity maintenance by automakers in a product development outsourcing scenario: the case of VW in Brazil. International Journal of Automotive Technology and Management, v. 7, n. 2/3, p. 200-215, 2007.

DIAS, A. V. C.; SALERNO, M. S. Condomínios Industriais: novas fábricas, novos arranjos produtivos e novas discussões na indústria automobilística brasileira, São Paulo, EPUSP, 1998.

DORAN, D.; ROOME, R. An Evaluation of Value-Transfer within a Modular Supply Chain. International Strategy and Research Operations Group, Kingston Business School, Kingston Hill, Kingston upon Thames KT2 7LB, 2003.

DORAN, D. et al. Supply chain modularisation: Cases from the French automobile industry. International Journal Of Production Economics, v. 106, n. 1, p. 2-11, 2007.

DORAN, D. Manufacturing for synchronous supply: a case study of Ikeda Hoover Ltd. Integrated Manufacturing Systems, v. 13, n. 1, p. 18-24, 2002.

DORAN, D. Rethinking the supply chain: an automotive perspective. Supply Chain Management: An International Journal, v. 9, n. 1, p. 102-109, 2004.

DORAN, D. Supply Chain Implications of Modularization. International Journal of Operations and Production Management. v. 23, n. 3, p .316-326, 2003. 
DORAN, D. Supplying on a modular basis: an examination of strategic issues. International Journal of Physical Distribution \& Logistics Management, v. 35, n. 9, p. 654-663, 2005.

DORAN, D.; HILL, A.; HWANG, K.S.; JACOB, G. Supply chain modularisation: Cases from the French automobile industry. International Journal Of Production Economics, v. 106, n. 1, p. 2-11, 2007.

EKDAHL, F. e GUSTAFSSON, A. QFD: the Swedish experience. In: The Ninth Symposium on Quality Function Deployment, Novi: Michigan, p.15-27, 1997.

FIXSON, S. K. The multiple faces of modularity - a literature analysis of a product concept for assembled hardware products. Technical report. 03-05 Industrial \& Operations Engineering, University of Michigan, 2003.

FIXSON, S. Product architecture assessment: A tool to link product, process, and supply chain design decisions. Journal of Operations Management, v. 23, n 3-4, p. 345-369, 2005.

FRAGOSO, H. R. O ciclo de desenvolvimento do produto da Volkswagen caminhões e ônibus. Anais CONGRESSO BRASILEIRO DE GESTÃO DE DESENVOLVIMENTO DE PRODUTOS, Belo Horizonte, p. 25-28, 1999.

FREDRIKSSON, P. Operations and logistics issues in modular assembly processes: cases from the automotive sector. Journal of Manufacturing Technology Management, v. 17, n. 2, p. 168-186, 2006a.

FREDRIKSSON, P. Mechanisms and rationales for the coordination of a modular assembly system: The case of Volvo Cars. International Journal of Operations \& Production Management, v. 26, n. 4, p. 350-370, 2006b.

FREDRIKSSON, P. Cooperation and conflict in modular production and supplier parks: the case of Volvo Cars' modular assembly system. International Journal of Automotive Technology and Management, v. 6, n. 3, p. 298-314, 2006c.

FRIGANT, V.; LUNG, Y. Geografical proximity and supplying relationships in modular production. International Journal of Urban and Regional Research, v. 26, n. 4, p. 742755, 2002.

GADDE, L.E.; JELLBO O. System sourcing - opportunities and problems. European Journal of Purchasing \& Supply Management, v. 8, n. 1, p. 43-51, 2002.

GRAZIADIO, T. Estudo Comparativo entre os Fornecedores de Componentes Automotivos de Plantas Convencionais e Modulares, São Paulo, EPUSP, Departamento de Engenharia de Produção, Tese de Doutorado, 2004.

GU, P.; SOSALE, S. Product modularization for life cycle engineering. Robotics and Computer Integrated Manufacturing, v. 15, n. 5, p. 387-401, 1999. 
HELPER, S.; MacDUFFIE, J. P.; PIL, F. et al. Modularization and Outsourcing: implications for the future of automotive assembly, In: International Vehicle Program (IMVP), 1999.

HOLMES, J. Re-scaling collective bargaining: union responses to restructuring in the North American auto industry. Geoforum, v. 35, n. 1, p. 9-21, 2004.

HUANG, C.C. Overview of Modular Product Development. Proc. Natl. Sci. Counc. ROC (A), v. 24, n. 3, 149-165, 2000.

HUMPHREY, J.; LECLER, Y.; SALERNO, M. Introduction. In: Global Strategies and Local Realities: the auto industry in emerging markets. London, Macmillaan, 2000.

ISHII, K.; YANG, T.G. Modularity: International industry benchmarking and research roadmap. Standford University. Chicago, 2003.

LARSSON, A. The development and regional significance of the automotive industry: supplier parks in western Europe. International Journal of Urban and Regional Research, v. 26, n. 4, p. 767-784, 2002.

Larsson, A. The development and regional significance of the automotive industry: supplier parks in western Europe. International Journal of Urban and Regional Research, v. 26, n. 4, p. 767-784, 2002.

LAU, A.K.W.; YAM, R.C.M. A case study of product modularization on supply chain design and coordination in Hong Kong and China. Journal of Manufacturing Technology Management, v. 16, n. 4, p. 432-446, 2005.

LEE, W.B. et al. A fuzzy analytic hierarchy process approach in modular product design. Expert Systems, v. 18, n. 1, p. 32-42, 2001.

LUNG, Y.; CHANARON, J.; FUJIMOTO, T.; RAFF, D. Coping with Variety in the auto industry. Hampshire (Inglaterra), Ashgate, 1999.

MARCONI, M.A.; LAKATOS, E.M. Técnicas de Pesquisa. São Paulo: Editora Atlas, 1996.

MARX, R. et al. The modular consortium in a new VW truck plant in Brazil: new forms of assembler and supplier relationship. Integrated Manufacturing Systems, v. 8, n. 5, p. 292-298, 1997.

MIKKOLA, J.H. Modularisation in New Product Development: Implications for Product Architectures, Supply Chain Management, and Industry Structures. PhD Thesis, Copenhagen Business School, Denmark, 2003.

MIKKOLA, J.H.; GASSMANN, O. Managing modularity of product architectures: toward an integrated theory. IEEE Transactions on Engineering Management, v. 50, n. 2, 2003. 
MIZUNO, S. Gerência para melhoria da qualidade: As Setes Novas Ferramentas de Controle da Qualidade, LTC - Livros Técnicos e Científicos Ed., 1993.

MUFFATTO, M.; ROVEDA, M. Developing product platforms: analysis of the development process. Technovation, v. 20, n. 11, p. 617-630, 2000.

ORSATO, R.J.; WELLS, P. U-turn: the rise and demise of the automobile industry. Journal of Cleaner Production, v. 15, n. 11-12, p. 994-1006, 2007.

PANDREMENOS, J. et al. Modularity concepts for the automotive industry: A critical review. CIRP Journal of Manufacturing Science and Technology, v. 1, n. 3, p. 148152, 2009.

PÉREZ, M.P.; SANCHEZ, A. M. Lean production and supplier relations: a survey of practices in the Aragonese automotive industry. Technovation, v. 20, n. 12, p. 665676, 2000.

PERSSON, M. Effects of changing a module's interface: a case study in an automotive company. International Journal of Automotive Technology and Management, v. 6, n. 3, p. 331-345, 2006.

PINE II, B. J. Mass Customization: The New Frontier in Business Competition. Boston: Harvard Business School Press, 1992.

PIRES, S. Gestão de cadeias de suprimento e o modelo de consórcio modular, Revista de Administração, São Paulo, v. 33, julho - setembro, 1998.

PIRES, S. R. I. New productive systems in the automotive industry: the current situation of three innovative plants in Brasil. International Journal of Automotive Technology and Management, v. 2, n. 1, p. 46-62, 2002.

RAMALHO, J.; SANTANA, M. A Indústria automobilística no Rio de Janeiro: relações de trabalho em um contexto de desenvolvimento regional, In: NABUCO, M.; NEVES, M.; NETO A. (org). Indústria Automotiva: a nova geografia do setor produtivo, Rio de Janeiro, DP\&A, 2002.

ROZENFELD, H. et al. Gestão de Desenvolvimento de Produto: uma referência para a melhoria do processo. São Paulo: Saraiva, 2006.

SALERNO, M. S. The characteristics and the role of modularity in the automotive business. International Journal of Automotive Technology and Management, v. 1, n. 1, p. 92-107, 2001.

SALERNO, M.; DIAS A. Product Design Modularity, Modular Production, Modular Organization: the evolution of modular concepts, In: Rencontre Internationale du GERPISA 8, Paris, 2000.

SALERNO, M. S. et al. Modularity ten years after: an evaluation of the Brazilian experience. International Journal of Automotive Technology and Management, v. 8, n. 4, p. 373-381, 2008. 
SALERNO, M. S. et al. The importance of locally commanded design for the consolidation of local supply chain: the concept of design headquarters. International Journal of Automotive Technology and Management, v. 16, n. 4, p. 361-376, 2009.

SALERNO, M.; ZILBOVICIUS, M.; ARBIX, G. Mudanças e persistências no padrão de relações entre montadoras e autopeças no Brasil. Revista de Administração, v.33, n.3, p. 16-28, 1998.

SALERNO, M.; MARX, R.; ZILBOVICIUS, M. et al. A Nova Configuração da Cadeia Automotiva Brasileira, São Paulo, EPUSP - PRO, 2002.

SANCHEZ, R.; MAHONEY, J. Modularity, flexibility, and knowledge management in product and organization design. Strategic Management Journal, v. 17, pp. 63-76, 1996.

SANCHEZ, R.; COLLINS, R.P. Competing - and Learning - in Modular Markets. Long Range Planning, v. 34, n. 6, p. 645-667, 2001.

SCAVARDA, L.F. et al. Comparação entre as tendências e estratégias da indústria automotiva no Brasil e na Europa. Gestão \& Produção, v. 12, n. 3, p. 361-375, 2005.

SHIBATA, T. et al. Empirical analysis of evolution of product architecture Fanuc numerical controllers from 1962 to 1997. Research Policy, v. 34, n. 1, p. 13-31, 2008.

SILVA, S.L. DA; ROZENFELD, H. Model for mapping Knowledge Management in product development: a case study at a truck and bus manufacturer. International Journal of Automotive Technology and Management, v. 7, n. 2/3, p. 216-234, 2007.

SPATH, D.; BAUMEISTER M. Synchronization of material flow and assembly in hybrid and modular systems. Assembly Automation, v. 21, n. 2, p. 152-157, 2001.

STURGEON, T.J. Modular Production Networks: A New American Model of Industrial Organization. Industrial Performance Center. MIT, Cambridge, MA Industrial and Corporate Change, 2002.

SVENSSON, G. Supplier segmentation in the automotive industry - A dyadic approach of a management model. International Journal of Physical Distribution \& Logistics Management, v. 34, n.1/2, p. 12, 2004.

VAN HOEK, R.I.; WEKEN, H. A. M. The Impact of Modular Production on the Dynamics of Supply Chains. The International Journal of Logistics Management, v. 9, n. 2, p. 35-50, 1998.

VELOSO, F.; FIXSON, S. Make-Buy Decisions in the Auto Industry: New Perspectives on the Role of the Supplier as an Innovator. Technological Forecasting and Social Change, v. 67, n. 2-3, p. 239-257, 2001.

VOSS, C. et al. Case Research in Operations Management. International Journal of Operations \& Production Management, v. 22, n. 2, p. 195-219, 2002. 
WHEELWRIGHT, S.C.; CLARK, K.B. Revolutionizing Product Development. Quantum Leaps in Speed, Efficiency and Quality. New York: The Free Press, 1992.

YIGIT, A. et al. Optimizing modular product design for reconfigurable manufacturing. Journal of Intelligent Manufacturing, v. 13, n. 4, p. 309-316, 2002.

YIN, R.K. Estudo de caso: planejamento e métodos. 2.ed. Porto Alegre: Bookman, 2001.

ZHANG, G.W.; Zhang, S.C.;Xu, Y.S. Research on flexible transfer line schematic design using hierarchical process planning. Journal of Materials Processing Technology, v. 129, n. 1-3, p. 629-633, 2002.

ZILBOVICIUS, M.; MARX, R.; SALERNO, M.S. A comprehensive study of the transformation of the Brazilian automotive industry. International Journal of Automotive Technology and Management, v. 2, n. 1, p. 10-23, 2002.

ZILBOVICIUS, M. Modelos para Produção, Produção de modelos: gênese, lógica e difusão do modelo japonês de organização de produção. São Paulo: Annablume, 1999. 